\title{
Measuring Retail Visual Cues Using Mobile Bio-metric Responses
}

\author{
Dishman, Paul; Groves, Joshua; Jolley, Dale \\ Marketing Department and the Vivint Neuromarketing Research SMARTLab, Utah Valley \\ University, USA
}

\begin{abstract}
This research provides the results of a comprehensive in-store study that utilized eye tracking to determine the initial eye attractiveness of signage and displays used in a Toyota retail dealership. Potential car buyers $(n=24)$ walked randomly through the showroom for the first time, and were asked to view the various signs, displays, video monitors, decorations, and vehicles on display. Research was conducted while the dealership was open in order to include distractions from human interaction. Subjects' eye movements and the objects viewed were captured using Tobii II eye tracking glasses at 60Mhz. A typical showroom self-tour lasted approximately 4:31 minutes. Subjects were then shown their results and Retrospective Think Aloud interviews were conducted with the subjects to determine positive and negative reactions to the observed objects. Signage measured included those required by Toyota, as well as those created by the dealership. Types of signage measured included digital, video, posters, stand-up cards, and ads placed on the vehicle. Each potential eye attractive object was identified and classified by type (signage, décor, digital signage, vehicle information, etc.). Every subject's results were analyzed by the number of fixations and the time spent viewing each object. The study revealed that video or digital messaging was not any more effective than static signage, but that placement of the signage was a determining factor in the effectiveness of message receptivity. Many of the non-signage objects received more attention than did certain types of advertising signage. The various attributes of the objects and signs that received positive attention were analyzed as to their eye attactiveness characteristics. Although signage in a retail showroom is believed to be critical in providing advertising and product messages, this study (in its particular environment) demonstrated that signage is not viewed by customers as often as previouly thought.
\end{abstract}

Keywords: In-Store Signage, Retail, Store Layout, Toyota, Automotive

This work is licensed under a Creative Commons License CC BY-NC-ND 4.0

Editorial Universitat Politècnica de València 